\title{
A concorrência padrão x não-padrão em língua escrita: duas variantes em foco
}

\author{
Genivaldo Guimarães dos Santos
Complexo Integrado de Educação (CIEl) \\ Gessilene Silveira Kanthack ${ }^{2}$ \\ Universidade Estadual de Santa Cruz (UESC)
}

Standard vs. non-standard concurrence in written: two variants in focus

\begin{abstract}
- RESUMO: Neste artigo, apresentamos os resultados de uma pesquisa que investigou o uso variável de ter $X$ haver, com sentido de existir, e ter auxiliar modal na estrutura ter de e ter que seguida de verbo infinitivo, com sentido de necessidade ou obrigação, a fim de verificar se as variantes consideradas não-padrão estão implementadas ou não em língua escrita monitorada. Para tanto, utilizamos como corpus entrevistas veiculadas em dois suportes, Revista Veja, de circulação nacional, e Jornal A Tarde, de circulação regional. Para fundamentar o trabalho, recorremos a pressupostos teóricos de duas vertentes sociolinguísticas, a Variacionista e a Educacional.
\end{abstract}

- PALAVRAS-CHAVE: Variação; Variantes; Língua escrita; Ensino.

- ABSTRACT: In this article, we will show the research results which checked the use of variable of ter $\mathrm{X}$ haver, with the meaning of existir, and modal auxiliary verb ter into the structure ter de $\mathrm{X}$ ter que following by an infinitive verb, with the meaning of needing or obligation, in order to verify the considered variants of non-pattern are implemented or not in monitored written language. To this purpose, we used as a corpus published interviews in two medias, Veja Magazine, with national circulation, and A Tarde newspaper, with regional circulation. To support the work, we used theoretical assumptions from two sociolinguistic aspects, Variationist and Educational.

- KEYWORDS: Variation; Variants; Written language; Teaching.

Neste artigo, apresentamos os resultados de uma pesquisa realizada no âmbito do PROFLETRAS/UESC que investigou o uso de duas estruturas que estão em competição no português brasileiro. São elas: verbo ter $\mathrm{X}$ verbo haver, com valor existencial, e ter auxiliar modal na estrutura ter de $\mathrm{X}$ ter que seguida de verbo infinitivo, com sentido de necessidade ou obrigação. Como corpus, utilizamos entrevistas escritas veiculadas no ano de 2017, em dois suportes, Revista Veja, de circulação nacional, e Jornal A Tarde, de circulação regional. Dessa maneira, esperamos encontrar: (i) um uso variável e motivado das duas estruturas, e (ii) um uso acentuado das variantes consideradas não-padrão, aquelas que não são recomendadas por gramáticas de orientação normativa, mas que, de modo geral, são bem aceitas no português brasileiro e não geram preconceito por parte de quem as usam.

\footnotetext{
${ }^{1}$ Mestre em Letras, pelo Profletras da Universidade Estadual de Santa Cruz-UESC, Ilhéus-BA. Professor da Rede Estadual de Ensino, Itabuna-BA, Brasil. E-mail: genivaldoguimaraes6@gmail.com.

${ }^{2}$ Doutora em Linguística, pela Universidade Federal de Santa Catarina. Professora do Departamento de Letras e Artes, vinculada ao Programa de Pós-Graduação em Letras: Linguagens e Representações e ao Mestrado Profissional em Letras, da Universidade Estadual de Santa Cruz, Ilhéus-BA, Brasil. E-mail: gskanthack@yahoo.com.br.
} 
Para dar suporte à pesquisa, adotamos pressupostos da Sociolinguística Variacionista (cf. Labov (1972) [2008]; Tarallo (1986); Bagno (2007); Mollica; Braga (2015); entre outros), que, além de oferecer uma metodologia que permite captar a frequência e os fatores que motivam os usos variáveis de uma língua, nos orienta a repensar sobre heterogeneidade linguística, relação entre norma e variação, variantes estigmatizadas, variantes de prestígio, preconceito linguístico, enfim, questões que têm impacto significativo no ensino de língua portuguesa. Também, utilizamos pressupostos da chamada Sociolinguística Educacional (cf. Bortoni-Ricardo, 2004, 2005), que propõe levar para a sala de aula a discussão e a reflexão sobre a variação linguística.

Para fins práticos, o artigo está estruturado assim: na primeira seção, expomos pressupostos sociolinguísticos que sustentam a pesquisa e que norteiam as discussões sobre variação linguística e ensino; na segunda, apresentamos os resultados de nossa investigação prática à luz da metodologia sociolinguística; na terceira, visando contribuir com o desenvolvimento da reflexão sociolinguística, sugerimos algumas ações que podem ser realizadas no âmbito escolar. As considerações finais e as referências encerram o artigo.

\section{A língua(gem) numa perspectiva social: contribuições sociolinguísticas}

Partindo do pressuposto de que linguagem e sociedade estão indissoluvelmente entrelaçadas, a Sociolinguística defende a importância de estudar a língua efetivamente usada, "levando em consideração as relações entre a estrutura linguística e os aspectos sociais e culturais da produção linguística" (CEZARIO; VOTRE, 2008, p. 141). Para isso, é necessário recorrer à comunidade linguística, que, conforme Alkmim (2001, p. 31), "é um conjunto de pessoas que interagem verbalmente e que compartilham um conjunto de normas com respeito aos usos linguísticos". A propósito, é na comunidade linguística que, naturalmente, surge a variação linguística, uma propriedade funcional e inerente às línguas naturais.

Segundo Mollica (2015, p. 10), "a variação linguística constitui fenômeno universal e pressupõe a existência de formas alternativas denominadas variantes". Compreender e explicar o que motiva a variação é o objetivo principal da chamada Sociolinguística Variacionista (cf. LABOV (1972) [2008]). Para ela, a variação linguística é motivada por fatores de natureza social e estrutural, ambos operando "num conjunto complexo de correlações que inibem ou favorecem o emprego de formas variantes semanticamente equivalentes" (MOLLICA, 2015, p, 27).

O pressuposto assumido por essa vertente teórica é que a diversidade linguística é estruturada e organizada, podendo ser descrita e analisada sistematicamente. Ao assumir isso, a Sociolinguística tem possibilitado a compreensão de que não existe nenhum grupo social ou comunidade linguística que utilize a língua de forma "certa" ou "errada" quando se compara a linguagem de um grupo com outro. O falante se apropria das regras que tem conhecimento e, com elas, se comunica com quaisquer interlocutores e em quaisquer contextos de interação social. Significa dizer que "todas as línguas e variedades de uma língua são igualmente complexas e eficientes para o exercício de todas as funções a que se destinam" (CAMACHO, 2001, p. 68).

No entanto, em se tratando de ensino, o tema da diversidade linguística ainda não é abordado de forma adequada, pois, além de não tratar sistematicamente a diversidade linguística como fato, a escola prega uma tradição que costuma repassar a ideia de que existe "uma e somente uma língua correta e eficaz a todas as circunstâncias de interação" (CAMACHO, 2001, p. 68). Estamos nos referindo aqui à chamada norma- 
padrão, associada à concepção de língua assumida pelas gramáticas de orientação normativa e que, segundo Faraco (2008, p. 74), é um instrumento de política linguística criado para padronizar e fixar um padrão de língua "a ser tomado como regulador (normatizador) do comportamento dos falantes".

A propósito, é essa norma-padrão, considerada impropriamente como norma culta, que a escola adota como objeto de ensino, pois o pressuposto é que ela é a ideal. Segundo Scherre (2005, p. 16), isso faz crer "que há uma língua estruturalmente mais certa do que outra, que há um dialeto mais certo do que outro ou que há uma variedade mais certa do que outra", um tipo de avaliação que contribui diretamente para o preconceito linguístico, muito fortalecido pela ideia de que as diferenças linguísticas, particularmente as que são produzidas por indivíduos com pouca ou nenhuma formação escolar, provenientes de zona rural, de classe social baixa, de locais ou regiões culturalmente desvalorizados, compõem o modelo da deficiência, o que leva o aluno a acreditar que tudo o que não corresponde ao modelo idealizado de língua se constitui em "erro", "defeito".

De acordo com Camacho (2001, p. 69) "o modo como a língua é ensinada na escola pratica tradicionalmente o modelo da deficiência". Um modelo que considera as diferenças como desvios da norma-padrão, que coloca o falante em posição inferior, marginalizada, favorecendo, assim, o preconceito linguístico, atitude valorativa que consiste em discriminar um falante pelo modo de falar a sua língua.

Diferentemente, a Sociolinguística defende que "as variações de linguagem não devem passar por um crivo valorativo, já que não são mais que formas alternativas que o sistema linguístico põe à disposição do falante" (CAMACHO, 2001, p. 69). Nesse sentido, entendemos que o ensino da variedade padrão não deve ser substitutivo, e, sim, complementado com outras variedades, pois "as formas alternativas podem conviver harmoniosamente em sala de aula" (CAMACHO, 2001, p. 72).

Esse tipo de pressuposto, por sua vez, também é assumido pela chamada Sociolinguística Educacional (cf. Bortoni-Ricardo, 2004; 2005), vertente teórica que defende a necessidade de se desenvolver uma pedagogia que seja voltada para as diferenças sociolinguísticas e culturais dos alunos. Num de seus livros, essa autora defende que

[...] a escola não pode ignorar as diferenças sociolingüísticas. Os professores e, por meio deles, os alunos têm que estar bem conscientes de que existem duas ou mais maneiras de dizer a mesma coisa. E mais, que essas formas alternativas servem a propósitos distintos e são recebidas de maneira diferenciada pela sociedade. Algumas conferem prestígio ao falante, aumentando credibilidade e o poder de persuasão; outras contribuem para formar-lhe uma imagem negativa, diminuindolhe as oportunidades. Há que se ter em conta que essas reações dependem das circunstâncias que cercam a interação (BORTONIRICARDO, 2005, p.15).

$\mathrm{Na}$ visão dessa autora, questões desse tipo necessitam ser debatidas no âmbito educacional, no sentido de formar alunos conscientes do que seja uma língua e da necessidade de ampliação de sua competência comunicativa. Nessa formação, é preciso reconhecer que a diferença não pode ser tratada como algo marginalizado, mas como forma alternativa, que, ao lado de formas da norma-padrão, pode ser descrita e analisada sistematicamente. É preciso sim reconhecer os valores sociais atribuídos a elas, mas, acima de tudo, compreender que uma não é melhor que a outra. 
A escola, seguindo nessa direção, poderá promover reflexões no intuito de desmistificar crenças tão arraigadas em nossa sociedade, por exemplo, a existência de uma língua homogênea, representada por uma única norma, a chamada norma-padrão. É claro que ela precisa ser reconhecida e estudada, pois é por meio dela que o aluno conhecerá determinadas regras que lhe permitirão alcançar ascensão social. E que o papel da escola é apresentar essa norma específica ao aluno, mas não é ela apenas que deve ser reconhecida. Vivemos numa sociedade extremamente plural, cujas diferenças linguísticas são o espelho da estratificação socioeconômica e político-cultural. Logo, cabe à escola também reconhecer a diversidade como fato, e, como defende Faraco (2008, p. 71-72), é preciso entender "que a língua é em si o conjunto das variedades. Ou seja, elas não são deturpações, corrupções, degradações, da língua, mas são a própria língua: é o conjunto de variedades (de normas) que constitui a língua”.

\section{As variantes em foco: a nossa amostra}

Na condição de professor, entendemos que ensinar a norma-padrão não significa apenas ensinar as regras prescritas pelos manuais normativos, excluindo as variedades trazidas pelos alunos das suas vivências, mas orientá-los quanto aos valores sociais que cada variedade apresenta. É preciso conscientizá-los que a língua coloca a sua disposição inúmeras formas, estruturas, regras que se alternam e que servem a propósitos comunicativos diferentes.

É o que acontece com as variantes que pesquisamos: ter $\mathrm{X}$ haver, com sentido de existir, e ter de + verbo infinito $\mathrm{X}$ ter que + verbo infinito. Essas variantes, quando usadas, apresentam frequências diferenciadas, pois há fatores que motivam seus usos. Assim, como objetivo geral, investigamos o uso dessas variantes, a fim de verificar se as que são consideradas não-padrão estão implementadas ou não em língua escrita formal.

Elegemos como corpus o gênero entrevista escrita e publicada em dois suportes: Jornal A Tarde, de circulação diária no Estado da Bahia, e Revista Veja, de circulação nacional. A justificativa para a escolha do gênero se deve ao fato de ele ser, comumente, permeado de marcas da língua falada, modalidade em que a variação linguística é bastante natural. Considerando que a linguagem oral interfere no uso da escrita, a expectativa é encontrarmos, na entrevista escrita, variantes que são consideradas nãopadrão, mesmo sendo esse tipo de texto altamente monitorado, submetido ao processo de revisão cujos critérios seguem as regras prescritas gramaticalmente.

Outra expectativa envolve o suporte onde a entrevista é veiculada, o jornal e a revista, que apresentam suas peculiaridades em função do público alvo, da circularidade e da própria natureza de cada um. Por exemplo, o jornal, em geral, diário, contém gêneros que circulam com notícias ou fatos apenas do dia, o que já diferencia da revista que, no caso da Veja, é semanal. Sendo o suporte essencial para que o gênero circule na sociedade, o esperado é que ele tenha alguma influência na natureza do gênero suportado. Logo, acreditamos que esses dois suportes sejam motivadores de diferenças sociais quanto ao uso da língua.

Em termos sociolinguísticos, a nossa amostra foi composta de dois envelopes, que assim foram constituídos:

- Envelope 1: Verbo ter X haver - com sentido de existir: 
(1) a. Há núcleos de professores e alunos na universidade que tradicionalmente veem com desconfiança a aproximação com o setor privado. (VEJA, 06/09/2017).

b. Há muitos esforços em prol da manutenção dos empreendedores na formalidade. (A TARDE, 04/09/2017).

(2) a. Sabe que existe um remédio mas não tem acesso ao medicamento salvador. (VEJA, 04/10/2017).

b. Como sempre digo, a arte é libertadora: não tem paredes, muros e fronteiras. (A TARDE, 22/10/2017).

- Envelope 2: Verbo ter auxiliar $+d e+$ verbo infinitivo $\mathrm{X}$ Verbo ter auxiliar + $q u e+$ verbo infinitivo

(3) a. Para ele, as empresas terão de assumir novas responsabilidades. (VEJA, 20/09/2017).

b. O executivo terá de enfrentar a situação, achar uma solução, procurar algo novo. (A TARDE, 15/10/2017).

(4) a. Agora todos terão que obedecer a premissa de não roubar e não deixar roubar. (A TARDE, 01/10/2017).

b. Sem dúvida, hoje somos a maior de modo varejista do Brasil, somos líder de mercado e, para isso, tem que estar no Nordeste. (A TARDE, $15 / 10 / 2017)$.

Em cada envelope, temos, portanto, duas variantes, duas "formas alternativas que configuram um fenômeno variável, tecnicamente chamado de variável dependente" (MOLLICA, 2015, p. 10-11). Como se pode notar pelos envelopes, temos em evidência duas variantes que se encontram em relação de concorrência: padrão $\mathrm{X}$ não-padrão. Compreendemos que padrão corresponde ao que é prescrito e recomendado pelas gramáticas de orientação normativa.

Para a primeira variável dependente, a nossa hipótese foi: o verbo ter no sentido de existir deverá ser mais usado do que o verbo haver, por dois motivos: primeiro, seu uso já é consagrado na língua falada, como atestam as pesquisas sociolinguísticas, a exemplo de Vitório (2008), que indica que a substituição do haver pelo ter se encontra em estágio avançado; e segundo, essa substituição já é reconhecida, por gramáticas normativas, a exemplo de Cunha e Cintra (1985), como fato inerente ao português brasileiro.

Para a segunda variável dependente, a nossa expectativa foi: a variante ter que deverá ser a mais frequente, tendo em vista que ter de, variante considerada de prestígio, de uso formal, é pouco recorrente no português brasileiro. Além disso, o uso de ter que, assim como o uso de ter com sentido de existir, não estigmatiza o falante, estando essas variantes já internalizadas como estruturas regulares da língua portuguesa.

Na pesquisa sociolinguística, "uma variável é concebida como dependente no sentido que o emprego das variantes não é aleatório, mas influenciado por grupo de fatores (ou variáveis independentes) de natureza social ou estrutural" (MOLLICA, 
2015, p. 11). Assim, em nossa pesquisa, analisamos as variáveis dependentes em função do suporte onde a entrevista foi veiculada, Jornal A Tarde e Revista Veja. Para esse fator, as nossas hipóteses foram: por um lado, as variantes preconizadas pelas gramáticas normativas deverão ser usadas mais nas entrevistas veiculadas no suporte Revista Veja, tendo em vista que se trata de um periódico de circulação nacional com larga tradição editorial e um público leitor mais seleto; por outro, as variantes de natureza não-padrão deverão ser mais frequentes nas entrevistas do suporte Jornal A Tarde, por esse alcançar um público diversificado, que envolve vários estratos sociais da população.

Depois de identificar todas as variáveis, promovemos a análise quantitativa, que, na Sociolinguística, é relevante porque possibilita, em situações de competição, visualizar qual forma alternativa é mais frequente, qual tem mais vantagem sobre outra e quais fatores inibem ou favorecem determinada variante. Assim, o primeiro cômputo que apresentamos envolve a variável ter $\mathrm{X}$ haver:

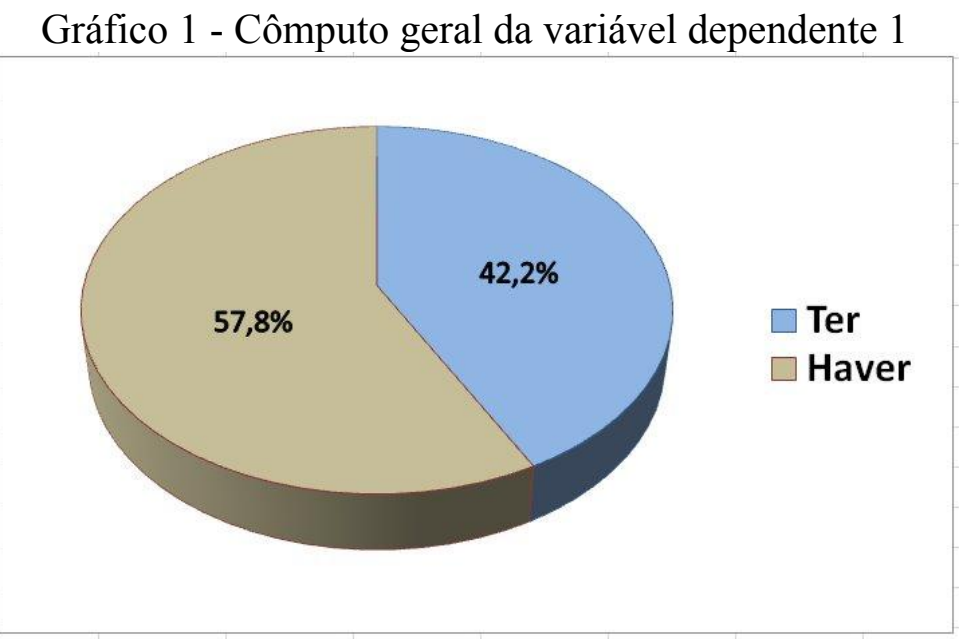

Fonte: elaboração própria

Como se pode notar, ter e haver, com sentido de existir, são usados de forma variável, com a frequência mais acentuada do verbo haver $(57,8 \%)$, contrariando a expectativa vislumbrada. Mesmo assim, os números do verbo ter $(42,2)$ indicam que seu uso está assegurado num gênero que requer alto grau de monitoramento linguístico, a entrevista escrita.

Quanto à segunda variável, vejamos o cômputo no gráfico 2: 
Gráfico 2 - Cômputo geral da variável dependente 2

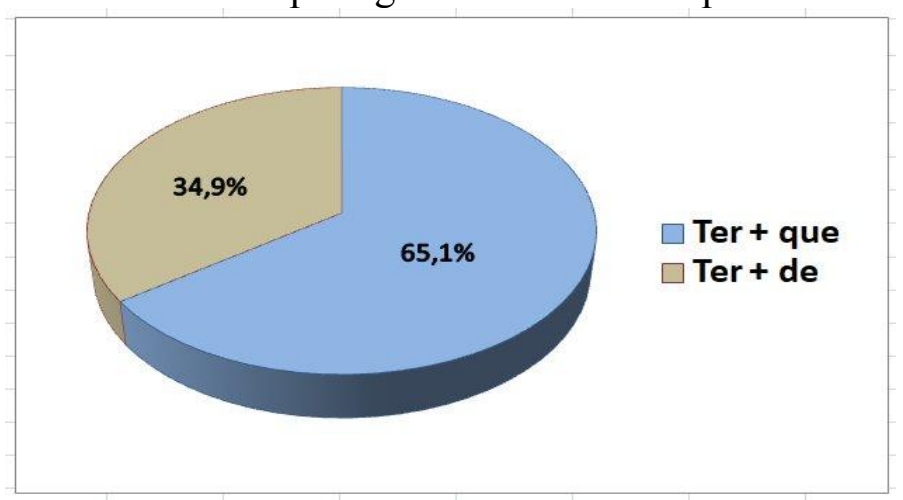

Fonte: elaboração própria

Das duas estruturas com valores equivalentes, a mais recorrente é a que apresenta o verbo ter acompanhado da conjunção que $(65,1 \%)$, julgada como a variante que não é de prestígio. Já a variante prescrita, verbo ter e preposição de $(34,9 \%)$, é a menos usada. Notamos que, apesar de os dois suportes veicularem linguagem monitorada, mesmo assim uma variante que não é de prestígio é mais usada do que a forma recomendada, confirmando, desse modo, a nossa expectativa de que a variante tem + que + infinitivo é bastante regular e sistemática na língua escrita.

Comparando os dois resultados, podemos afirmar que estamos diante de usos com valores sociais diferenciados. No gráfico 1 , temos a variante de prestígio sendo a mais usada, já, no gráfico 2, é o contrário: a variante estigmatizada é mais recorrente. Ou seja, parece haver uma restrição maior quanto ao uso de ter com valor existencial, e uma restrição menor para o ter que, como se essa fosse de fato a regra a ser seguida.

$\mathrm{Na}$ intenção de demonstrar a influência do fator suporte sobre os usos das variantes pesquisadas, apresentamos os gráficos 3 e 4 :

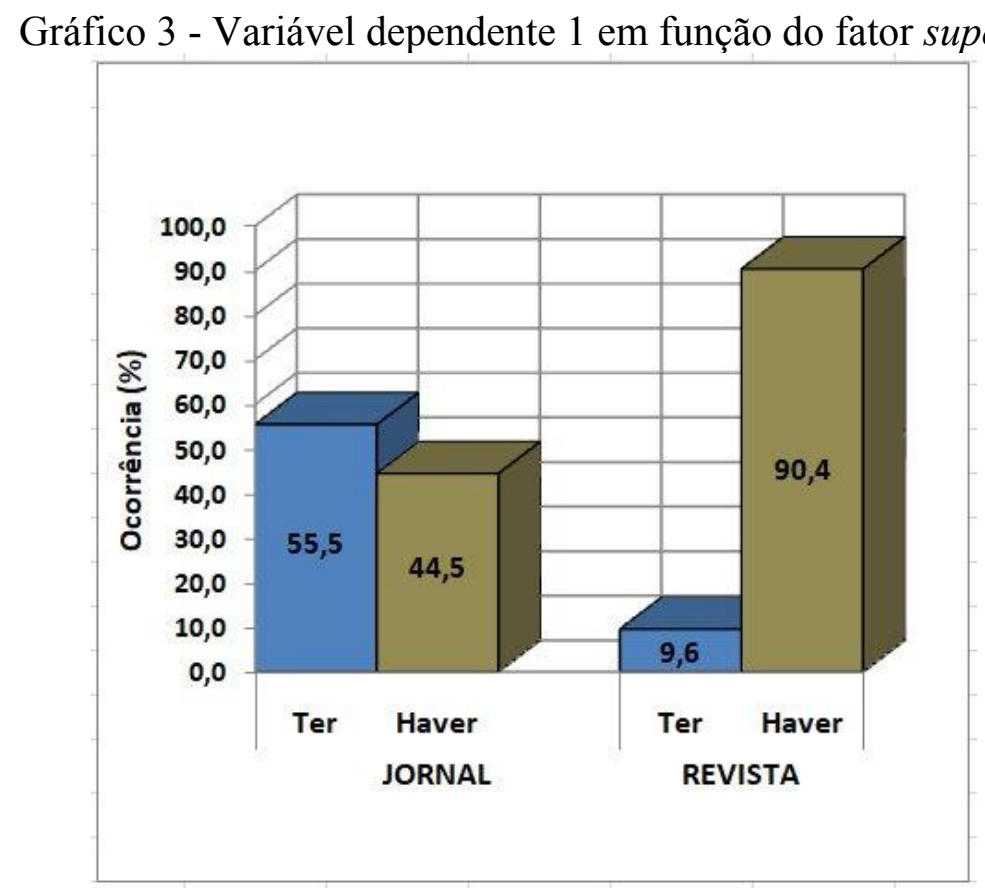

Fonte: elaboração própria

De fato, nossas expectativas se confirmam: os dois suportes fazem uso alternado de ter e haver. Notamos uma diferença acentuada entre a revista Veja e o jornal A Tarde

Traços de Linguagem, Cáceres, v. 4, n. 2, p. 25-36, 2020. 
quanto ao uso dos dois verbos. Por um lado, a revista privilegia o verbo haver $(90,4 \%)$ em oposição ao verbo ter $(9,6 \%)$, o que confirma o valor da variante de prestígio nesse tipo de suporte, em que a linguagem veiculada é de natureza formal. Por outro lado, no jornal, as diferenças não são tão contrastantes. Diferentemente da revista, nesse suporte é o verbo ter o mais recorrente (55,5\%), em oposição ao verbo haver (44,5\%). Claro que, por ser linguagem escrita monitorada, percebemos a força da norma com o uso do haver nas entrevistas veiculadas no jornal.

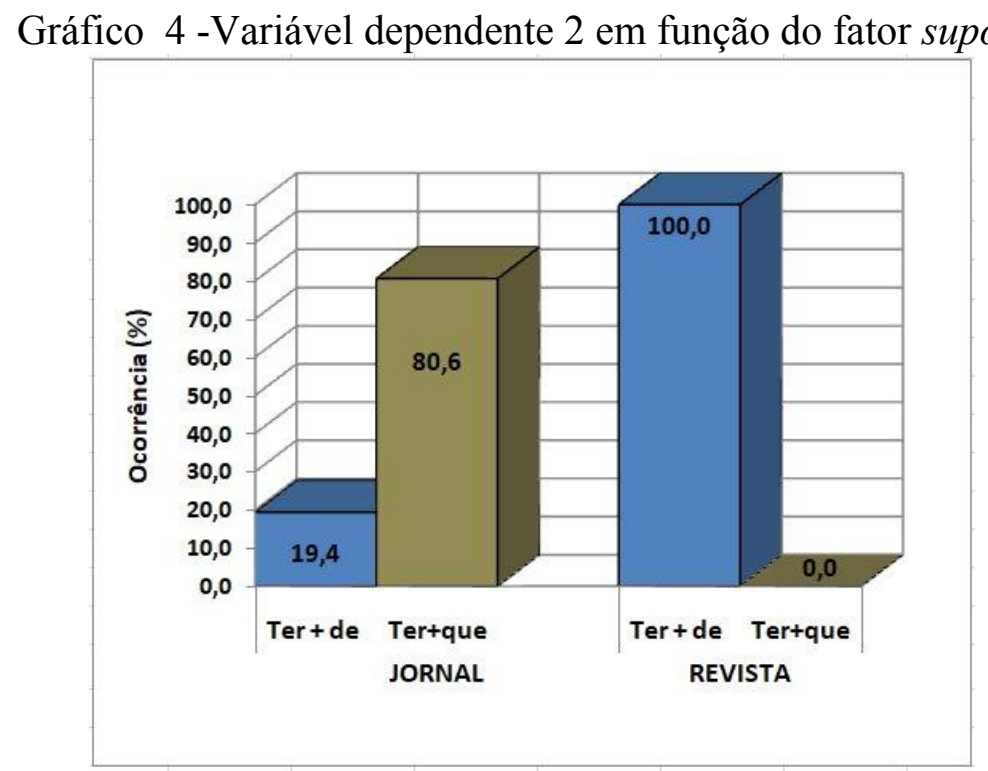

Fonte: elaboração própria

Temos um resultado indicando que, por um lado, a revista faz uso categórico da variante de prestígio (100\%), e, por outro, que o jornal alterna quanto ao uso das duas variantes, evidenciando que a escolha mais frequente é da estrutura que não é recomendada como padrão: ter que $(80,6 \%)$ em oposição a ter de $(19,4 \%)$.

Comparando os gráficos 3 e 4, notamos que, de fato, a revista privilegia formas que a tradição normativa recomenda. Já, no jornal, percebemos nitidamente competições mais acirradas entre as variantes padrão e não-padrão. Numa situação, ter e haver competem quase que de igual para igual, $55,5 \%$ e $44,5 \%$, respectivamente. $\mathrm{Na}$ outra situação, a diferença é bastante marcada: ter + de tem menos "força" do que ter + que, 19,4\% e 80,6\%, respectivamente. Ou seja, mesmo sendo um gênero veiculado num suporte em que a linguagem é monitorada, ele dá espaço para uma variante que é estigmatizada pela tradição.

De modo geral, percebemos que, embora os dois suportes prezem pelo monitoramento linguístico, tendo em vista sua natureza e sua funcionalidade, há neles presença de variantes que não são prescritas pelos manuais normativos, mas que estão assegurando seu lugar na modalidade escrita. Isso indica que essas variantes, ter e ter que, são aceitas pelos falantes como formas apropriadas também a contextos de escrita, pois elas não representam nenhum prejuízo para a comunicação. Isso nos leva a inferir que os falantes têm consciência de que essas estruturas, mesmo sendo condenadas, são previsíveis, atendem a regras do sistema da língua e denotam o mesmo valor de verdade daquelas que a tradição recomenda. 


\section{Variação linguística e reflexão sociolinguística na escola}

Defendemos, conforme a Sociolinguística Educacional, a necessidade de levar para a sala de aula a discussão e a reflexão sobre variação linguística. Aliás, reflexão sociolinguística é uma ação básica que, segundo Cyranka (2016), deve fazer parte da vida escolar do aluno desde os primeiros anos, para que ele vá construindo uma concepção de linguagem que permita reconhecer as diferenças não como deficiências, mas como variedades da língua. Nesse sentido, o professor deve apontar

[...] caminhos que levem seus alunos a dominar as diferentes variedades do português brasileiro, inclusive as cultas, tanto na modalidade oral quanto na escrita, tornando-se usuários autônomos e livres. Mais ainda: tornam-se abertos às diferenças, respeitando os que não tiveram a oportunidade de ter acesso à plenitude desse bem comum, que é a língua. (CYRANKA, 2016, p. 172).

A fim de contribuir com o trabalho do professor em sala de aula, sugerimos, aqui, algumas ações que podem ser utilizadas para desenvolver, no aluno, a reflexão sociolinguística:

- Aplicação de atividades que permitam ao aluno reconhecer que em qualquer ato comunicativo, seja ele falado ou escrito, o falante pode usar a língua de forma variável e que não é apenas na língua falada que ocorre a variação linguística, mas na escrita também. Regras variáveis podem ser demonstradas por meio da análise de diferentes gêneros, orais e escritos, veiculados em diferentes suportes, de estilos mais ou menos monitorados.

- Promoção de atividades que ofereçam ao aluno condições para entender que os usos da língua são práticas sociais e que muitas delas são especializadas, que exigem vocabulário específico, aplicação de regras gramaticais recomendadas pelas gramáticas de orientação normativa. Isso pode ser feito por meio de gêneros formais, seja de fala ou de escrita, para que ele perceba os recursos linguísticos que são apropriados a esses gêneros especializados.

- Execução de atividades que proporcionem ao aluno observar como fenômenos linguísticos são descritos em gramáticas normativas e como eles se manifestam na língua efetivamente usada. Isso pode ser feito pela observação direta, envolvendo diferentes falantes, diferentes grupos sociais, diferentes textos. Da observação, pode-se fazer uma análise quantitativa, demonstrando, por exemplo, quantos falantes usaram uma regra determinada pela gramática normativa, quantos não usaram; se a regra prescrita foi mais usada por homens ou mulheres, por falantes mais ou menos escolarizados, por falantes mais velhos ou mais novos; se a regra prescrita foi utilizada ou não num texto especializado, num texto de menos formalidade. Com esse tipo de pesquisa, o aluno tem a oportunidade de compreender mais amplamente a questão da heterogeneidade linguística.

- Realização de atividades que proporcionem ao aluno visualizar diferenças dialetais e estilísticas, diferenças que envolvam os eventos de comunicação. Tratar essas diferenças por meio de contínuos, conforme proposta de Bortoni-Ricardo (2004), é um bom caminho para o aluno compreender a variação no uso da língua. O contínuo de urbanização permite mostrar os diferentes falares, por exemplo, rurais de um lado, 
urbanos de outro; o contínuo de oralidade e letramento oportuniza dispor os eventos de comunicação, por exemplo, de um lado, eventos em que não há influência direta da língua escrita (oralidade), de outro, eventos mediados pela escrita (letramento); o contínuo da monitoração linguística possibilita perceber os diferentes estilos, por exemplo, de um lado, os monitorados, que exigem mais atenção e planejamento, e de outro, os não-monitorados, que requerem menos formalidade.

- Atividades que oportunizem ao aluno o reconhecimento da importância do monitoramento linguístico, necessário aos eventos comunicativos especializados. Por exemplo, se num evento de fala monitorada usou uma variante que não é apropriada, deverá saber que, em outra situação de mesma natureza, deverá monitorar de forma que aplique a variante recomendada. Se, por exemplo, num texto escrito, cujo grau de monitoramento é máximo, usou uma regra não prescrita, deverá sim fazer o ajuste necessário, visando cumprir com as exigências que aquele texto impõe.

Aqui, claro, elencamos apenas algumas sugestões de atividades que poderão ser realizadas em salas de aula no intuito de promover a reflexão sociolinguística. Para que isso ocorra com êxito, defendemos a necessidade do professor assumir uma postura de pesquisador, criando situações para que o aluno possa produzir o seu próprio conhecimento. Concordamos com Bagno (2007, p. 195) quando afirma que "a pesquisa estimula o desenvolvimento da habilidade investigativa, da intuição, da análise crítica, da interpretação, do questionamento dos conhecimentos cristalizados, da abertura para o novo". Ou seja, por meio da pesquisa, professor e aluno poderão refletir sobre os usos que os falantes fazem da língua, encontrar explicações científicas para eles, enfim, produzir um conhecimento próprio do funcionamento da língua nas suas práticas sociais.

\section{Considerações finais}

Este trabalho nos possibilitou verificar, na prática, usos efetivos envolvendo duas variantes que estão em competição no português brasileiro. Foram elas: ter $\mathrm{X}$ haver, com valor existencial, e ter auxiliar modal na estrutura ter de e ter que seguida de verbo infinitivo, com sentido de necessidade ou obrigação. A análise do corpus (entrevistas escritas veiculadas no ano de 2017, em dois suportes, Revista Veja e Jornal A Tarde) evidenciou que, embora submetidas às regras de normatização e revisão, que atendam um acentuado grau de monitoramento linguístico, nas entrevistas o uso das variantes é diferenciado.

Por um lado, vimos um uso variado dos verbos ter e haver, com a indicação de que a segunda variante é mais recorrente, já que se trata de um gênero de língua escrita. No entanto, quando levado em consideração o fator suporte, verificamos uma diferença acentuada: de um lado, a revista privilegia o verbo haver, do outro, o jornal indicia uma frequência maior do verbo ter.

Por outro, para a variável ter + de e ter + que, os resultados apontaram a variante não-padrão como a mais recorrente, mesmo sendo o gênero de língua escrita monitorada. O contraste é acentuado quando se observa a influência do fator suporte: categoricamente, a revista faz uso da variante de prestígio, ter + de, já o jornal privilegia a estrutura que não é recomendada como padrão, ter que, evidenciando que essa escolha, por parte do falante, é consciente e que se trata de uma variante que não prejudica a qualidade da informação veiculada. Ou seja, mesmo havendo um processo 
de revisão e monitoramento da escrita, não impediu que o uso de estruturas contrárias às regras prescritas como padrão fosse recorrente.

Essa constatação põe em evidência um dos princípios básicos da Sociolinguística, o de que o uso diferenciado dessas variantes indica o dinamismo que envolve a língua e os falantes, podendo isso ser captado por uma metodologia como a que utilizamos nesta pesquisa. Também evidenciamos, por meio dos pressupostos apresentados, as contribuições que essa área da Linguística tem proporcionado para o ensino da diversidade linguística. Compreendemos que, na condição de professor de língua portuguesa, devemos ter um olhar mais criterioso e ponderado sobre o fenômeno da variação linguística, buscar fundamentos teóricos consistentes para abordar o tema em sala de aula.

\section{Referências}

ALKMIM, T. Sociolinguística-Parte I. In: MUSSALIN, F; BENTES, A. C. (Orgs.). Introdução à Linguística: domínios e fronteiras. Vol. 1. São Paulo: Cortez, 2001, p. 29-30.

BAGNO, M. Nada na língua é por acaso: por uma pedagogia da variação linguística. São Paulo: Parábola Editorial, 2007.

BORTONI-RICARDO, S. M. Educação em língua materna: a sociolinguística na sala de aula. São Paulo: Parábola Editorial, 2004.

BORTONI-RICARDO, S. M. Nós cheguemu na escola, e agora?: Sociolinguística e educação. São Paulo: Parábola Editorial, 2005.

CAMACHO. R. G. Sociolingüística. In: MUSSALIM, F.; BENTES, A. C. (Orgs.). Introdução à Linguiística: domínios e fronteiras. v.1. São Paulo: Cortez, 2001, p. 4975 .

CEZARIO, M. M.; VOTRE, S. Sociolingüística. In: MARTELOTA, M. E. (Org.). Manual de Lingüística. São Paulo: Contexto, 2008, p. 141-155.

CUNHA, C.; CINTRA, L. Nova gramática do português contemporâneo. Rio de Janeiro: Nova Fronteira, 1985.

CYRANKA, L. Sociolinguística aplicada à educação. In: MOLLICA, M. C; FERRAREZI JUNIOR, C. (Orgs.). Sociolinguística, sociolinguísticas: uma introdução. São Paulo: Contexto, 2016. p. 167-176.

FARACO, C. A. Norma culta brasileira: desatando alguns nós. São Paulo: Parábola editorial, 2008.

LABOV, W. Padrões Sociolinguísticos. São Paulo, Parábola Editorial, 2008 [1972].

MOLliCA, M. C.; BRAGA, M. L. (Orgs.). Introdução à Sociolinguística: o tratamento da variação. 4.ed., São Paulo: Contexto, 2015. 
MOLLICA, M. C. Fundamentação teórica: conceituação e delimitação. In: MOLLICA, M. C.; BRAGA, M. L. (Orgs.). Introdução à sociolinguística: o tratamento da variação. 4.ed., São Paulo: Contexto, 2015, p. 9-14.

MOLLICA, M. C. Relevância das variáveis não linguísticas. In: MOLLICA, M. C.; BRAGA, M. L. (Orgs.). Introdução à sociolinguística: o tratamento da variação. 4.ed., São Paulo: Contexto, 2015, p.27-31.

SCHERRE, M. M. P. Doa-se lindos filhos de poodle: variação linguística, mídia e preconceito. São Paulo: Parábola, 2005.

TARALLO, F. A pesquisa sociolinguística. São Paulo: Ática, 1986.

VITÓRIO, E. G. de S. L. A. Ter/Haver existenciais na escrita de alunos dos ensinos fundamental e médio da cidade de Maceió-AL. 2008,117 f. Dissertação de Mestrado. Universidade Federal de Alagoas/UFAL, Maceió, 2008.

Recebido em: agosto de 2020. Aprovado em: dezembro de 2020.

Como citar este trabalho:

SANTOS, G. G. dos; KANTHACK, G. S. A concorrência padrão x não-padrão em língua escrita: duas variantes em foco. Traços de Linguagem. v. 4, n. 2, p. 25-36, 2020. 